\title{
Microsurgical anatomy of the artery of Adamkiewicz and its segmental artery
}

\section{Cargill H. Alleyne, Jr., M.D., C. Michael Cawley, M.D., George G. Shengelaia, M.D., and Daniel L.} Barrow, M.D.

Departments of Neurosurgery and Radiology (Division of Neuroradiology), Emory University School of Medicine, Atlanta, Georgia

Object. The blood supply of the lower spinal cord is heavily dependent on the artery of Adamkiewicz, which characteristically originates from one of the thoracolumbar segmental arteries. The aforementioned artery is of enormous clinical, surgical, and radiological importance, and the goal of this study was to elucidate the course and branches of the segmental artery that gives rise to this important vessel.

Methods. In this cadaveric, microsurgical anatomical study, the authors investigate and describe the course and branches of the artery of Adamkiewicz and the segmental branch from which it ultimately originates. A review of the literature is provided.

Conclusions. By documenting the microsurgical anatomy of these important vessels, this study facilitates an understanding of the anatomy that will aid in treatment planning for surgery of various lesions in this area.

Key Words * arteria radicularis magna * artery of Adamkiewicz * blood supply * microsurgical anatomy * spinal cord * vascular anatomy * anatomical study

The vascularization of the lower spinal cord generally depends on a single artery originating from one of the thoracolumbar segmental arteries. This vessel was initially described in 1882 by Adamkiewicz[1] as the "magnus ramus radicularis anterior." The artery of Adamkiewicz is of enormous clinical, surgical, and radiological importance: it frequently feeds into various spinal lesions, including tumors and vascular malformations of the spine. The anatomical localization of the artery of Adamkiewicz is important in planning the surgical and/or interventional radiological treatment of these lesions. The preoperative localization of this artery with the aid of selective angiography is also important in the surgical treatment of thoracoabdominal aortic aneurysms and transthoracic spine procedures. The anatomical knowledge gained preoperatively may reduce the risk of postoperative paraplegia. Although the radiological and gross anatomy of the artery of Adamkiewicz has been described in the literature, its microsurgical anatomy is less well documented. In this cadaveric, microsurgical anatomical study we sought to elucidate the course and branches of the lateral and middle trunks of the segmental artery that gives rise 
to the artery of Adamkiewicz. The course and branches of the artery of Adamkiewicz (middle trunk) are described.

\section{MATERIALS AND METHODS}

The thoracolumbar spines from 10 previously embalmed adult cadavers were harvested with the segmental arteries from the aorta intact. In the first three cadavers processed, the aorta was cannulated and irrigated with saline. A colored silicone rubber mix was prepared by adding red tempera paint powder (Sargen Art, Inc., Hazelton, PA) to the liquid solvent polydimethylsiloxane (Dow Corning, Inc., Midland, MI). The silicone rubber (3110 RTV silicone rubber; Dow Corning) was mixed with the solvent at a ratio of 1:3. A catalyst (1-Catalyst; Dow Corning) was added just before injection. The rubber mix was then injected into the aorta. The anterior vertebral body was removed to expose the dura, taking care to preserve the lateral aspect of the body and its relationship with the surrounding soft tissue. A midline durotomy was made and the characteristic hairpin turn of the artery of Adamkiewicz was identified. The specimen was cropped around the segmental artery at that level (Fig. 1). In the other seven cadavers the anterior aspect of the vertebral body was removed before irrigation of any vessel. Again, the lateral aspect of the vertebral body and its relationship to surrounding tissue was preserved. The durotomy was made and the hairpin turn of the artery of Adamkiewicz sought. Once identified, the segmental artery at that level was selectively cannulated and irrigated with saline and then with the rubber mix. After at least 48 hours, the anatomical dissection was performed with the aid of a surgical microscope. The course and diameter of the initial portion of the segmental artery deep to the fascial plane investing the psoas muscle attachment or diaphragmatic attachment to the lateral vertebral body was noted. The course and diameter of the lateral, middle, and medial trunks were observed and recorded. The branches of the respective segments were also noted. All measurements were made using a millimeter ruler and calipers.

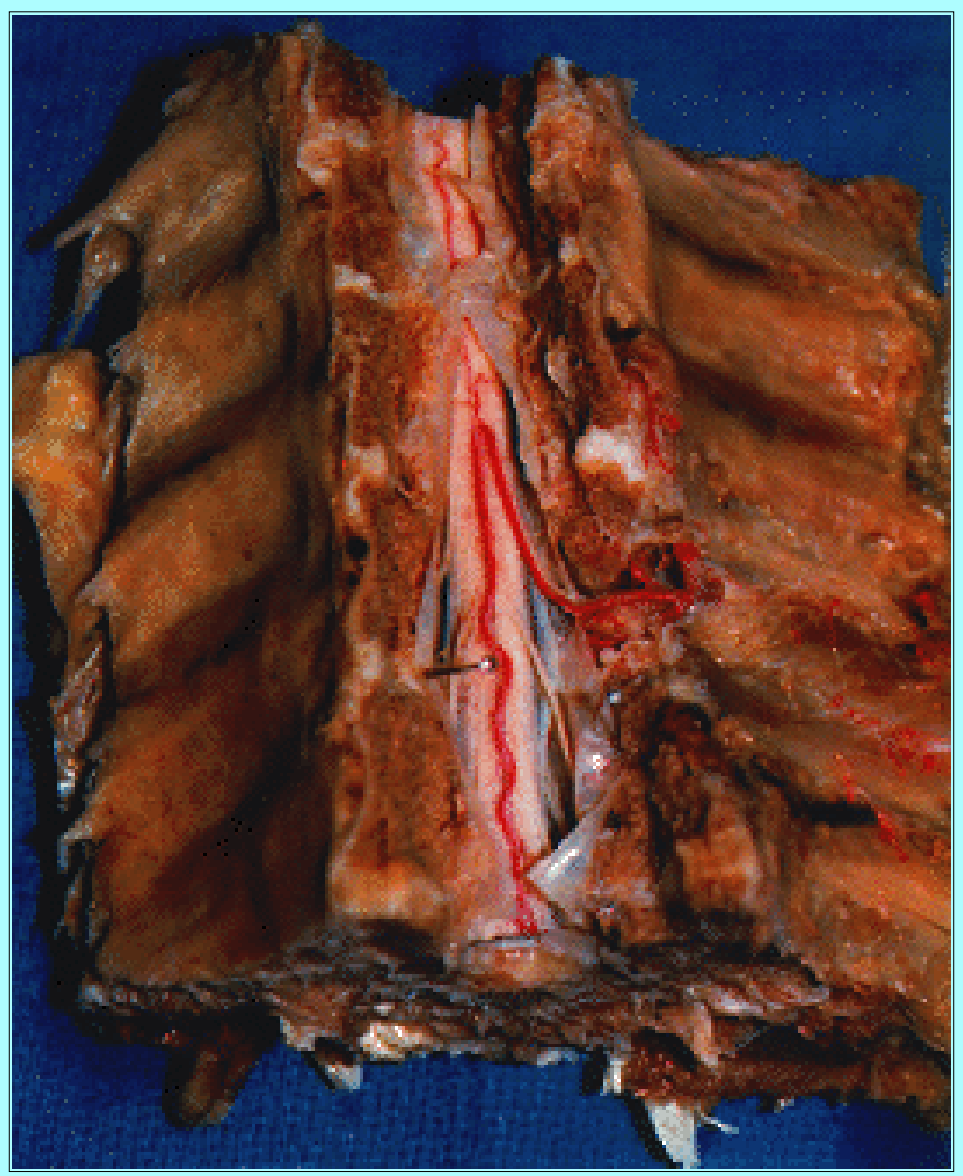


Fig. 1. Photograph showing the ventral view of a cropped thoracolumbar segment of a cadaveric spine.

\section{RESULTS}

\section{Initial Segment}

The initial portion of the segmental artery was 9 to $26 \mathrm{~mm}$ in length (average $16.9 \mathrm{~mm}$ ). Its diameter at the psoas or diaphragmatic fascia averaged $2.7 \mathrm{~mm}$ (range $2.3-3 \mathrm{~mm}$ ). This segment coursed dorsolaterally along the lateral aspect of the vertebral body and gave rise to numerous branches (2-13 in each specimen, with an average of 4.5), which supplied the paravertebral soft tissue (Fig. 2). Thirty-nine of these branches were found in nine specimens and the average diameter at the origin was $0.53 \mathrm{~mm}$ (range $0.2-1 \mathrm{~mm}$ ). The distance to these branches from the origin of the initial segment ranged from 2 to $50 \mathrm{~mm}$ (average $16.1 \mathrm{~mm}$ ).

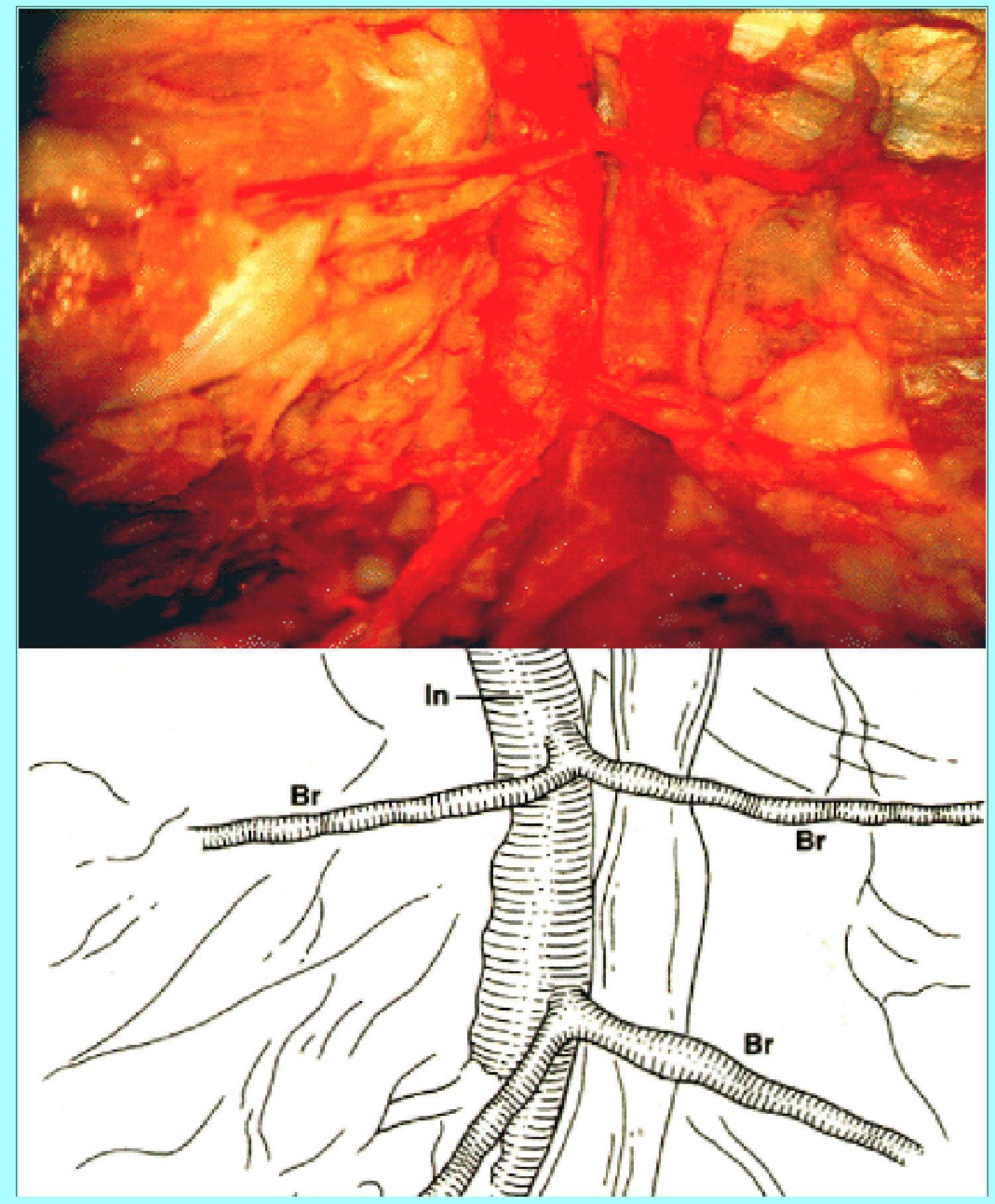




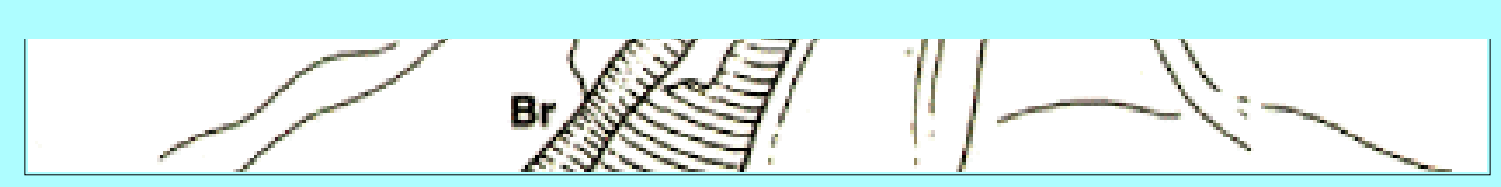

Fig. 2. Upper: Photograph of cadaveric specimen illustrating the initial portion of the segmental artery distal to the fascial plane investing the psoas or diaphragmatic attachment to the lateral vertebral body. Note numerous branches supplying the paravertebral soft tissue. Lower: Schematic drawing depicting the vessels seen in the upper panel. $\mathrm{Br}=$ branches of the initial portion; In = initial portion of the segmental artery.

\section{Lateral Trunk (Anterior Ramus and Intercostal Artery)}

The initial segment either bifurcated into the lateral trunk (anterior ramus) and the common origin (posterior ramus) of the medial and middle trunks or trifurcated into each of the three trunks (Fig. 3). The lateral trunk coursed laterally from the vertebral body, and the diameter at its origin averaged $2.21 \mathrm{~mm}$ (range 1.5-3.2 $\mathrm{mm}$ ). One to three twigs branched from the proximal portion of the lateral trunk at an average distance of $11.05 \mathrm{~mm}$ (range $3-23 \mathrm{~mm}$ ) from the origin of the lateral trunk. The average diameter of the 15 twigs in seven specimens was $0.43 \mathrm{~mm}$ (range $0.1-1 \mathrm{~mm}$ ). These twigs supplied blood to intercostal muscle and fat (Fig. 3 upper and lower left).

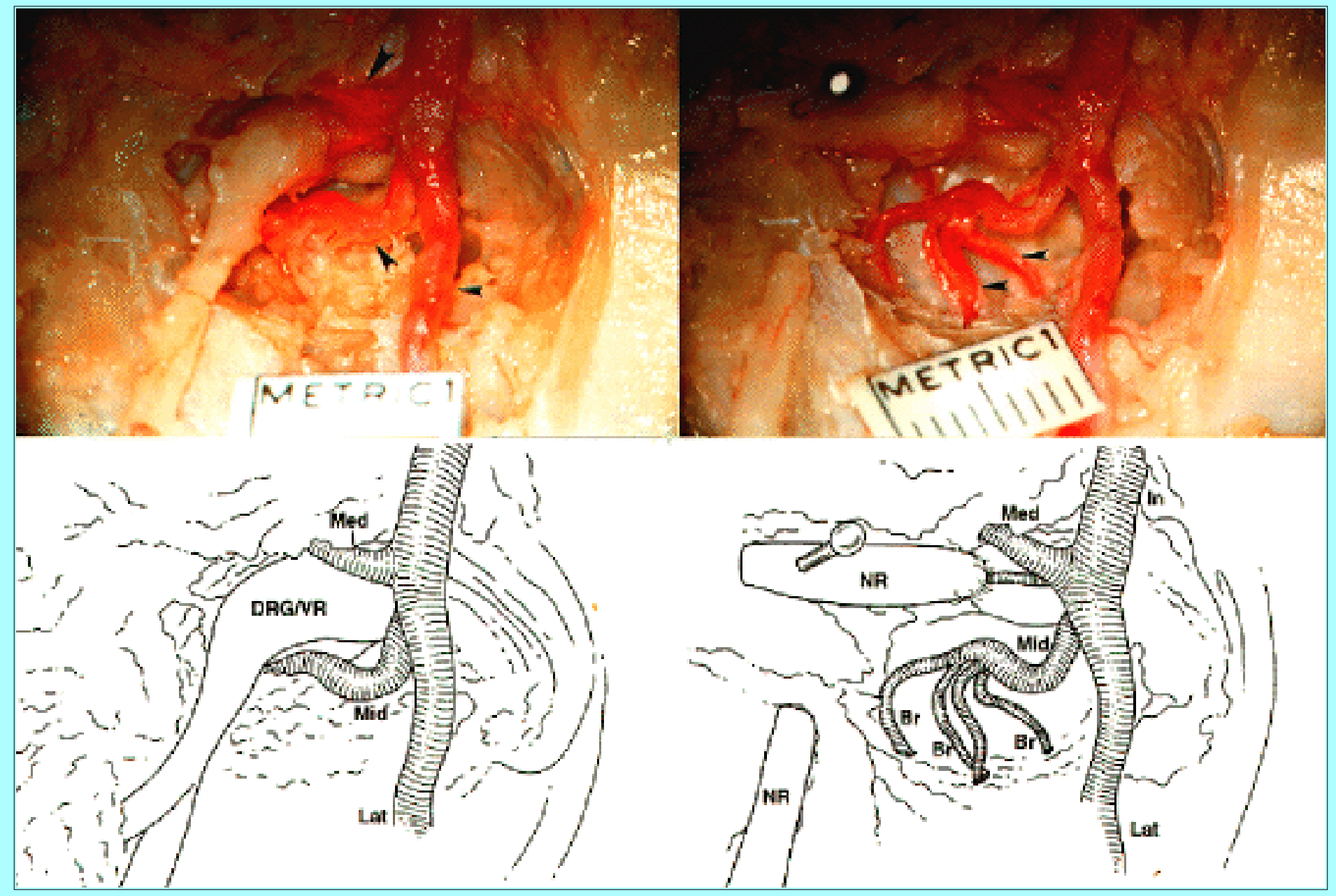

Fig. 3. Upper Left: Photograph of cadaveric specimen illustrating the trifurcation of the initial portion of the segmental artery into lateral (small arrowhead), middle (medium arrowhead), and medial (large arrowhead) trunks. Lower Left: Schematic drawing depicting the structures seen in the upper left panel. Upper Right: Photograph showing cadaveric specimen in which the nerve root has been retracted to show branches of the middle trunk 
(arrowheads). Lower Right: Schematic drawing depicting the structures seen in the upper right panel. $\mathrm{Br}=$ branches of the middle trunk; $\mathrm{In}=$ initial segment; Lat = lateral trunk; Med $=$ medial trunk; Mid = middle trunk; $\mathrm{NR}=$ nerve root.

\section{Middle Trunk (Muscular and Dorsal Branches)}

The middle trunk coursed lateral to the spinal column in a dorsal direction and the average diameter at its origin was $1.64 \mathrm{~mm}$ (range 1-2 mm). Branches from the middle trunk numbered one to five per specimen (average 3.4) and supplied the soft tissue of the caudal foramen, caudal aspect of the nerve, perineural venous plexus, and intercostal muscle and soft tissue (Fig. 3 upper and lower left). The branches of the middle trunk arose 0.5 to $17 \mathrm{~mm}$ (average $7.25 \mathrm{~mm}$ ) from the origin of that artery.

\section{Medial Trunk (Artery of Adamkiewicz, Great Radicular Artery, and Arteria Radiculomedullaris Magna)}

An artery of Adamkiewicz was found in each of nine cadavers; in one cadaver this artery was not found but two small radiculomedullary vessels were examined (see Discussion). In seven cadavers the artery of Adamkiewicz originated from the left, whereas in two cadavers it originated from the right. The origin of this vessel was from T9-10 in two specimens, from T10-11 in two, from T11-12 in one, from T12-L1 in one, from L1-2 in one, and indeterminate in two.

The diameter of the origin of the artery of Adamkiewicz (which typically branched from a common origin with the middle trunk) ranged from 1.2 to $2.5 \mathrm{~mm}$ (average $1.89 \mathrm{~mm}$ ). The main trunk of this vessel coursed medially through the rostral or midportion of the foramen and was closely juxtaposed to the dorsal root ganglion-ventral root (DRG-VR) complex at its rostral and ventral aspect (Fig. 4). At this point, the vessel generally made a gentle turn rostrally alongside the nerve to pierce the dura (Fig. 4). 


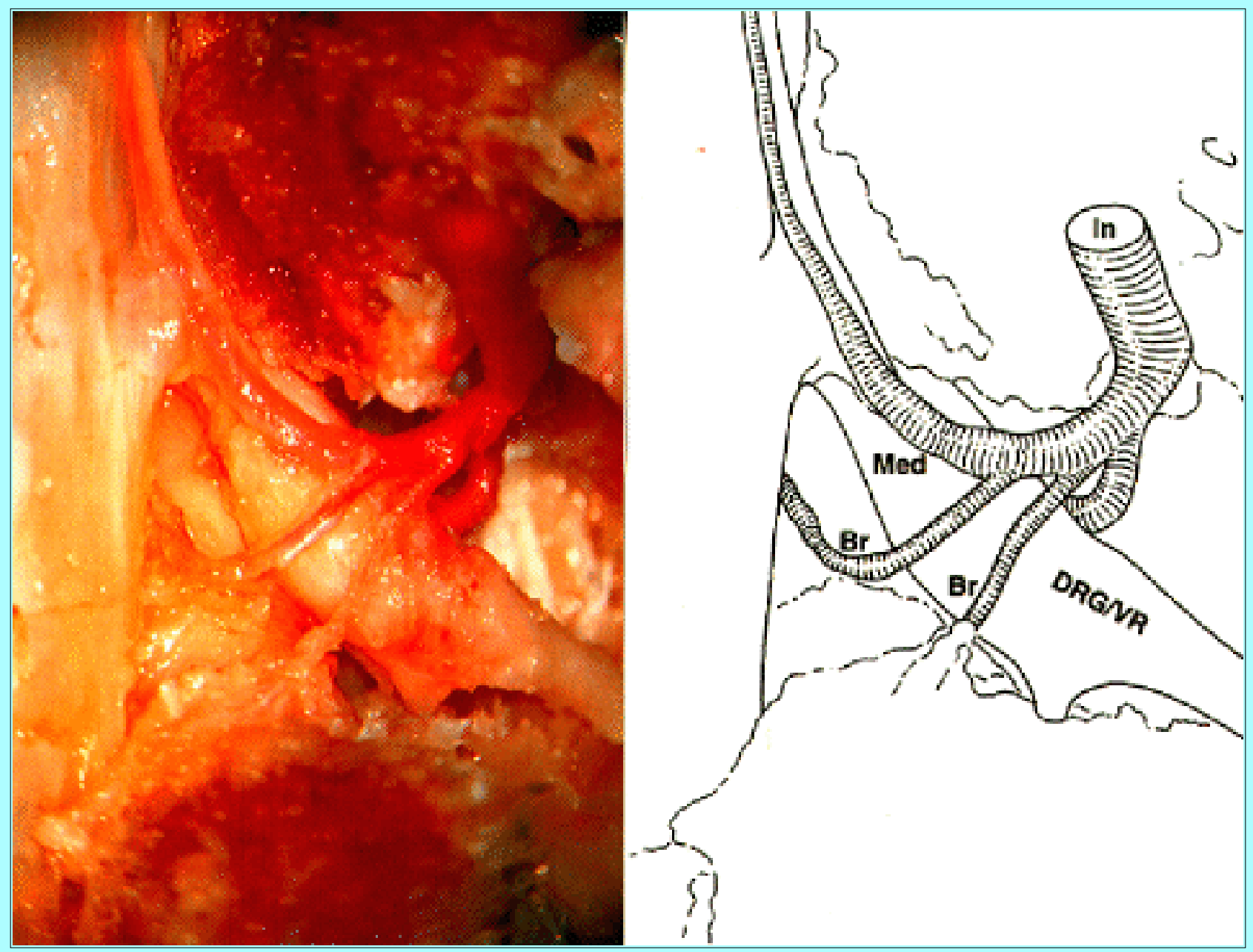

Fig. 4. Left: Photograph of cadaveric specimen showing a ventral view of the branches of the medial trunk supplying structures in and around the DRG-VR complex and foramen. Note the gentle turn rostrally as the medial trunk pierces the dura. Right: Schematic drawing depicting the structures seen in the left panel. See legend to Fig. 3 for definitions of abbreviations.

At the point of dural entry there was occasionally a slight caudal turn. The artery then traveled with the VR to the ventral surface of the spinal cord, where it took a characteristic hairpin turn caudally (Fig. 5). The anterior spinal artery connected with the artery of Adamkiewicz at or just before the hairpin turn (Fig. 5). 


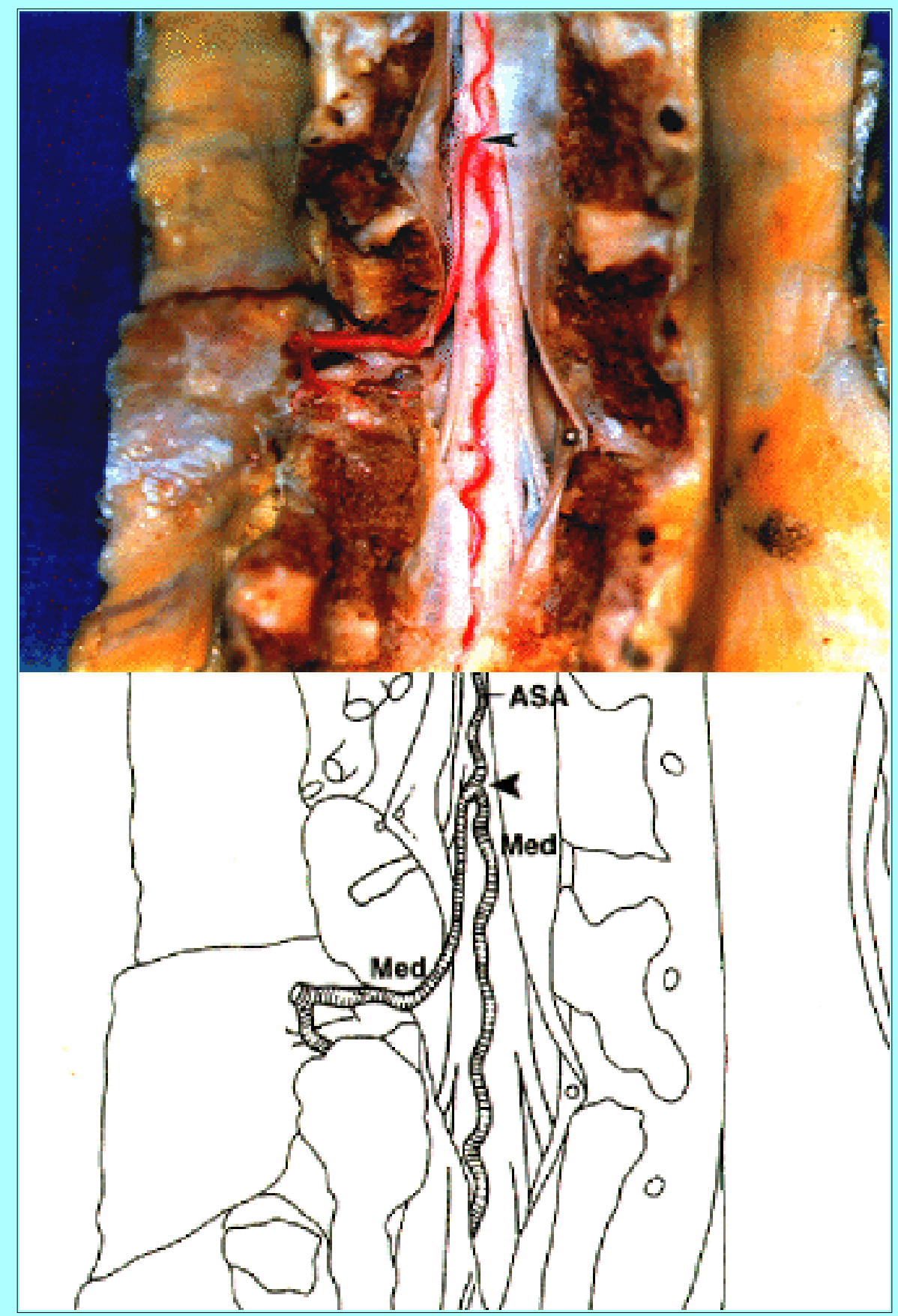

Fig. 5. Upper: Photograph of cadaveric specimen illustrating the hairpin turn of the artery of Adamkiewicz. Note the connection with the anterior spinal artery (arrowhead). Lower: Schematic drawing depicting the structures seen in upper panel. ASA = anterior spinal artery; Med $=$ medial trunk, artery of Adamkiewicz.

The branches of the artery of Adamkiewicz numbered 2 to 6 (average 3.7) and originated 0.5 to $11 \mathrm{~mm}$ (average $4.67 \mathrm{~mm}$ ) from the origin of the parent vessel. These branches supplied a variety of structures including the caudal and occasionally rostral aspect of the foramen, DRG, VR, and venous plexus at the dorsal and caudal aspect of the DRG in the vicinity of the axilla of the nerve root (Figs. 4a and b). A branch (dorsal radicular artery) also coursed along the ventrolateral aspect of the dorsal rootlets to the spinal cord (Fig. 6). At their origin, the branches of the artery of Adamkiewicz averaged $0.48 \mathrm{~mm}$ in diameter (range 0.1-1.2 mm). 


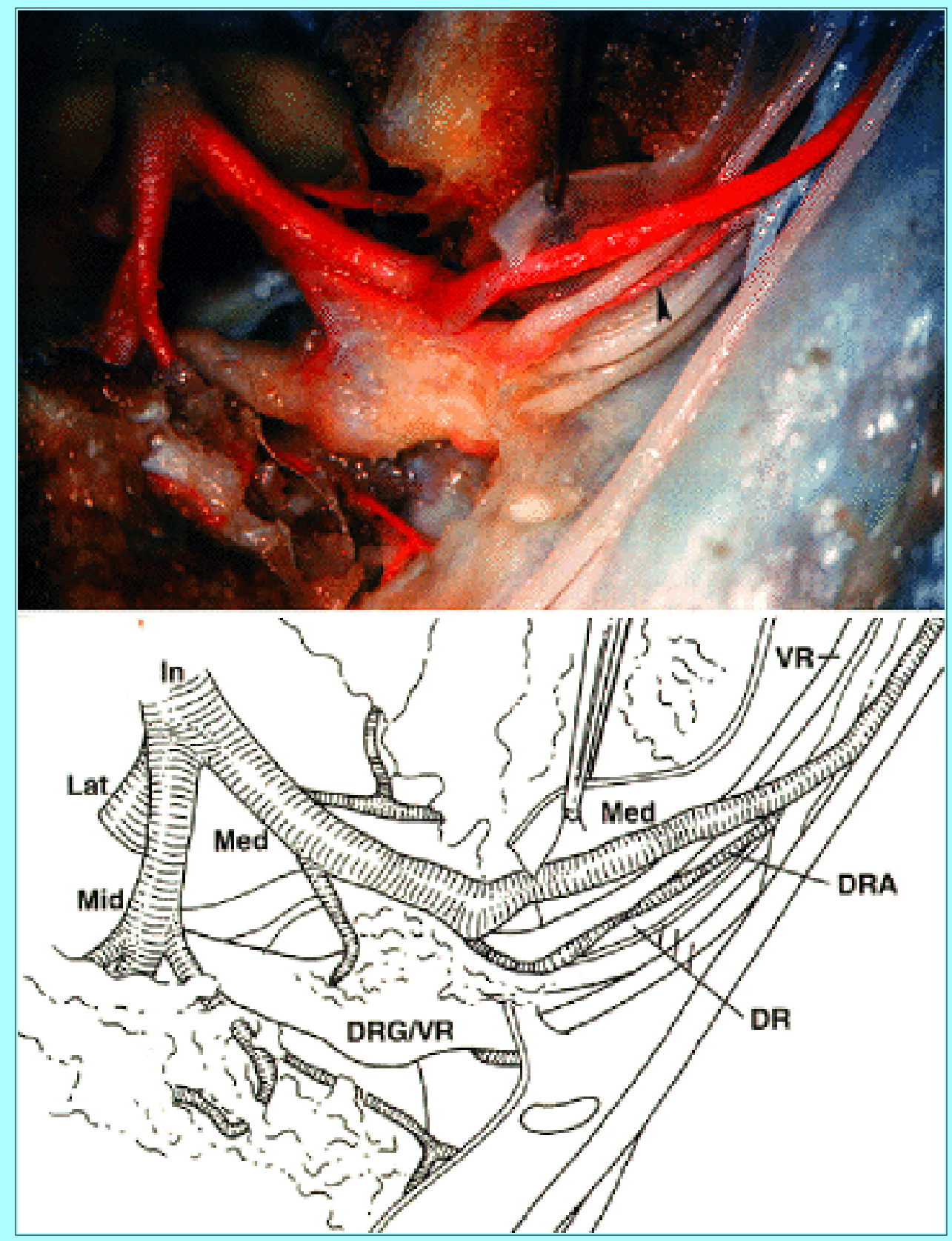

Fig. 6. Upper: Photograph of cadaveric specimen in which the dorsal radicular artery (arrowhead) is seen traveling ventral to the dorsal rootlets. Lower: Schematic drawing depicting the structures seen in the upper panel. DR = dorsal rootlets; DRA = dorsal radicular artery; see Fig. 3 for definitions of common abbreviations.

The diameter of the artery of Adamkiewicz narrowed progressively from its origin to the junction with the anterior spinal artery at the hairpin turn. At the DRG, the foramen, and the point of dural entry, the diameter of the artery of Adamkiewicz averaged $1.84 \mathrm{~mm}$ (range 1.2-3 mm), $1.53 \mathrm{~mm}$ (range 0.9-2 $\mathrm{mm}$ ), and $1.2 \mathrm{~mm}$ (range 0.8-1.7 mm), respectively. The diameter of the intradural segment averaged $1.08 \mathrm{~mm}$ (range 0.8-1.5 mm), whereas the diameter at the hairpin turn averaged $0.92 \mathrm{~mm}$ (range $0.7-1.2 \mathrm{~mm}$ ).

\section{Control Arteries}

In one specimen, no artery of Adamkiewicz was identified. Instead, two control radiculomedullary arteries, one at T12-L1 and the other at L1-2, were explored. The initial lengths of the segmental arteries were 22 and $17 \mathrm{~mm}$, respectively, and the diameter of each at its origin was $2.2 \mathrm{~mm}$. The number of 
branches of each was nine and 12, and the average diameter of these branches at their origin was 0.58 $\mathrm{mm}$. The diameter of the lateral trunk at its origin was 1.1 and $2 \mathrm{~mm}$ in each specimen. There was one main branch from the lateral trunk in one specimen and four branches from the lateral trunk in the other; the average diameter of these branches was $1 \mathrm{~mm}$. The average diameter of the middle trunk at the origin was $1.15 \mathrm{~mm}$, whereas that of the medial trunk was $1 \mathrm{~mm}$. The medial trunk coursed ventral to the DRG-VR complex and pierced the dura to travel with the VR.

\section{DISCUSSION}

The classic description of the vascular supply of the spinal cord as composed of a single anterior spinal artery and two posterior spinal arteries reinforced at each level by the radiculomedullary arteries was challenged by von Haller.[6] In 1882 Adamkiewicz[1] provided conclusive evidence that not all the radicular arteries reach the spinal cord and described the "magnus ramus radicularis anterior" as the main feeding vessel to the lower spinal cord. Several authors, including Kadyi,[2] Tanon, [5] and more recently, Rodriguez-Baeza, et al.,[4] have confirmed the nonsegmental and nonsymmetric vascular supply of the spinal cord.

The fact that the artery of Adamkiewicz was not found in one of our cadavers does not necessarily mean that it was not present. The thoracolumbar specimens used in this study were cropped from the lower thoracic spine; however, the artery of Adamkiewicz can arise as high as at the T-5 level.[3] Thus, it is possible that the artery in question was outside our area of study. Most commonly (in $75 \%$ of cases), it arises from T-9 to T-12 or from L1-2 (in 10\% of cases).[3] These percentages are consistent with the results of our study. The artery of Adamkiewicz arose from the left in $78 \%$ and from the right in $22 \%$ of the nine specimens in our study in which it was found. This is also consistent with the left-sided predominance documented in the literature.[4]

The relationship of the artery of Adamkiewicz to the nerve root in the foramen deserves further mention. The artery of Adamkiewicz was consistently found at the rostral or middle portion of the foramen, ventral and slightly rostrolateral to the DRG-VR complex. This relationship should be borne in mind during thoracolumbar procedures. The branches of the artery of Adamkiewicz frequently included one to the dorsal nerve root (equivalent to the posterior radicular artery). It is also notable that the intradural portion of the artery of Adamkiewicz proximal to the junction with the anterior spinal artery was consistently devoid of branches. In our study, the average diameter of the artery of Adamkiewicz at the spinal cord $(0.92 \mathrm{~mm}$, range $0.7-1.2 \mathrm{~mm})$ was almost identical to that reported in the study by Rodriguez-Baeza, et al.[4] (0.9 mm, range 0.6-1.2 mm).

In summary, we have documented the microsurgical anatomy of the artery of Adamkiewicz and the segmental artery from which it originates. The results of this study should facilitate an understanding of the surgical anatomy of this important vessel.

\section{Acknowledgment}

We thank Gary D. Bonner, M.B.A., for his invaluable technical assistance in preparing the specimens.

\section{References}

1. Adamkiewicz A: Die Blutgefässe des menschlichen Rückenmarkes. II Theil. Die Gefässe der Rückenmarksoberfläche. Sitzb Akad Wiss 85:101-130, 1882 
2. Kadyi H: Uber die Blutgefässe des Menschlichen Rückenmarkes. Lemberg: Gubrynowicz \& Schmidt, 1889

3. Lazorthes G, Gouaze A, Zadeh JO, et al: Arterial vascularization of the spinal cord. Recent studies of the anastomotic substitution pathways. J Neurosurg 35:253-262, 1971

4. Rodriguez-Baeza A, Muset-Lara A, Rodriguez-Pazos M, et al: The arterial supply of the human spinal cord: a new approach to the arteria radicularis magna of Adamkiewicz. Acta Neurochir 109:57-62, 1991

5. Tanon L: Les Arterès de la Moelle Dorso-Lombaire. Thesis. Paris: 1908

6. von Haller A: Iconum Anatomicarum. Quibus Aliquae Partes Corporis Humani Delineatae Traduntur. Gottingen: Apud viduam Abrami Vandenhoeckii, 1754

Manuscript received December 2, 1997.

Accepted in final form May 29, 1998.

Address reprint requests to: Daniel L. Barrow, M.D., Department of Neurosurgery, The Emory Clinic, 1365-B Clifton Road, NE, Atlanta, Georgia 30322. 